\title{
ATUAÇÃO DO PROFISSIONAL DO SERVIÇO SOCIAL NA EDUCAÇÃO ESPECIAL
}

\author{
ACTION OF THE SOCIAL SERVICE PROFESSIONAL IN \\ SPECIAL EDUCATION
}

Naila Muhammad El Abed ${ }^{\mathrm{I}}$

\section{RESUMO}

A presente pesquisa tem o objetivo de caracterizar a atuação do profissional do serviço social na educação especial, especificamente na Associação de Pais e Amigos dos Excepcionais (APAE), verificando as suas atribuições em prol da garantia dos direitos sociais da pessoa com necessidades especais. Para isso, foi realizada uma análise descritiva de projetos realizados que envolvem as pessoas com deficiências bem como suas famílias, articulando ações em prol dos estudantes que frequentam a APAE e entrevistas com duas profissionais do serviço social dessa instituição. É possível sugerir que o profissional do serviço social desempenha um papel importante na APAE sendo que as profissionais entrevistadas demonstram comprometimento com a população atendida e têm desenvolvido um trabalho ancorado no Projeto Ético-Político do Serviço Social. Seus projetos procuram atender as vulnerabilidades sociais e territoriais, as fragilidades nos vínculos afetivos e as construções de relação de poder.

Palavras-chave: APAE. Educação Especial. Serviço Social.

\section{ABSTRACT}

The present research has the objective of characterizing the social service professional 's performance in special education, specifically in the Association of Parents and Friends of the Exceptional (APAE), verifying their attributions in favor of guaranteeing the social rights of the person with special needs. For this, a descriptive analysis of projects carried out involving people with disabilities as well as their families was carried out, articulating actions in favor of the students who attend the APAE and interviews with two professionals of the social service of this institution. It is possible to suggest that the social service professional plays an important role in the APAE, since the professionals interviewed demonstrate commitment to the population served and have developed a work anchored in the EthicalPolitical Project of Social Service. Its projects seek to address social and territorial vulnerabilities, weaknesses in affective bonds, and constructions of power relations.

Keywords: APAE. Special education. Social service.

Trefeitura Municipal de Nova Andradina - Mato Grosso do Sul /Brasil. E-mail: nailaabed@ hotmail.com 


\section{INTRODUÇÃO}

Atualmente os assistentes sociais têm e desenvolvem atribuições inseridas no âmbito da elaboração, execução e avaliação de políticas públicas, assim como na assessoria a movimentos sociais e populares. De acordocom CFESS (2011) as competências pertinentes a esse profissional permitem realizar uma análise crítica da realidade, estruturar seu trabalho e definir as competências e atribuições específicas necessárias ao enfrentamento das situações e demandas sociais que se apresentam em seu cotidiano.

Sob essa ótica, tal profissional pode atuar, em diversos espaços, sejam eles privados, governamentais e não governamentais, em áreas como: educação, saúde, habitação, assistência, reabilitação, previdência social, sistema penitenciário e outros segmentos (IAMAMTO, 2000)

A profissão de assistente social é regulamentada e, para exercê-la, é necessário cursar a graduação em Serviço Social, em faculdade reconhecida pelo MEC e obter o registro no Conselho Regional de Serviço Social (CRSS).

Considerando que o serviço social está presente na educação, este projeto de pesquisa tem como proposta de estudo a caracterização da atuação do assistente social na educação especial, especificamente na Associação de Pais e Amigos dos Excepcionais (APAE). Também será observada a atuação desse profissional direcionada para a inserção das famílias de estudantes na APAE.

A atuação do assistente social pode ocorrer em qualquer área, pois sua intervenção é imprescindível para as questões sociais das pessoas. Afirmando esse enfoque Iamamoto (2009) pontua que os profissionais do Serviço Social desenvolvem suas ações profissionais, seja na formulação ou na execução das políticas sociais, em diversas áreas, como educação, saúde, previdência e assistência social, habitação, trabalho e meio ambiente, entre outros, movidos pela defesa de ampliação dos direitos dos cidadãos.

O trabalho profissional do assistente social caracteriza-se também pelo atendimento às demandas e necessidades sociais de seus usuários, e podem construir resultados concretos quer nas dimensões materiais, sociais, políticas e culturais da vida da população, facilitando seu acesso às políticas sociais (IAMAMOTO, 2009).

$\mathrm{O}$ assistente social, enquanto profissional inserido na política de educação, tem a possibilidade de garantir o acesso aos direitos de crianças e famílias em vulnerabilidade social, desde que atendidas as condicionalidades exigidas para recebimento dos benefícios sociais (LUNA et al. 2016)

Partindo desse pressuposto, sabe-se que educação inclusiva tem sido discutida por muitos educadores, ainda que tenhamos uma legislação vigente que garante educação para todos. Especificamente, desde a Constituição de 1988, define-se como um dos princípios para o ensino "a igualdade de condições de acesso e permanência na escola" (artigo 206, inciso I) e preconiza o "atendimento educacional especializado aos portadores de deficiência" (artigo 208). Esses dispositivos foram reforçados 
por outros documentos como o Estatuto da Criança e do Adolescente - ECA, Lei 8069 de 1990, em seu artigo 53 (inciso I) e artigo 54 (inciso III), a Declaração de Salamanca de 1994; e a atual Lei de Diretrizes e Bases da Educação Nacional - LDBEN, Lei 9394 de 1996.

Assim, a união entre serviço social e educação sugere um progresso no atendimentoa pessoas com deficiência e tende a fomentar melhorias nas ações realizadas pelo assistente social no setor educativo. Com vistas nesses aspectos, esta proposta de pesquisa busca descrever as práticas desse profissional em sua atuação na educação especial. Portanto, o objetivo macro deste estudo é caracterizar a atuação do profissional do serviço social na educação especial, especificamente numa unidade de APAE, localizada no Mato Grosso do Sul. Para isso, foram adotados os procedimentos metodológicos descritos a seguir.

\section{MATERIAL E MÉTODO}

Trata-se de uma pesquisa exploratória e descritiva, que, conforme Gil (2008) é aquela que permite uma maior familiaridade entre $\mathrm{o}$ pesquisando e o pesquisado (exploratória) e que tem por objetivo descrever as características de uma população, de um fenômeno ou de uma experiência; por isso, descritiva. Também foi feita uma revisão bibliográfica para conceituar e caracterizar as atividades desenvolvidas pelo profissional de Serviço Social na educação especial, incluindo os que tratavam dos atendimentos realizados com os estudantes e familiares na APAE.

Assim, realizou-se a pesquisa, numa unidade de APAE, com a análise documental, ou seja, dos projetos e das atividades realizadas pelo profissional do serviço social, incluindo os direcionados à acolhida das famílias e dos estudantes que frequentavam a instituição. Também foram realizadas entrevistas com duas profissionais do serviço social atuantes naquele espaço.

\section{RESULTADOS E DISCUSSÃO}

O assistente social contribui com a elaboração e execução de programas voltados à orientação de famílias e de alunos que frequentam a APAE. Assim, esse estudo coloca em destaque as políticas públicas na educação especial, articuladas às práticas que demonstram o avanço na atuação do profissional do serviço social nos espaços educativos da APAE.

\section{Atuação do Profissional de Serviço Social na Educação Especial}

As pessoas deficientes ocuparam diferentes papeis na história da humanidade. O tratamento destinado aos deficientes era arraigado de preconceito, sendo esses indivíduos excluídos totalmente do contexto social. Na idade antiga, (Grécia e Roma antigas, dentre outras) a sociedade tratava os deficientes como classes inferiores, sendo eles responsáveis pelos serviços braçais; em algumas outras sociedades, eles eram valorizados como força humana para a guerra ou para a agricultura; enfim, o contexto social dependia deles para sua sobrevivência, porém, em caso de deficiência física era considerada intolerável, matando-se os deficientes físicos no momento do nascimento (SASSAKI, 1997). 
Mazzotta (1999) por sua vez afirma que o contexto histórico sobre a inclusão de pessoas com deficiências, passou da marginalização para o assistencialismo e deste para a educação, reabilitação, integração social e, mais recentemente, para a inclusão social. Esse percurso não aconteceu de forma linear, pois essas diferentes posturas ainda convivem entre si e direcionam práticas e políticas públicas.

Tendo em vista o contexto histórico da educação inclusiva no Brasil, nos séculos XVIIe XVIII, é possível ver que se evidenciam teorias e práticas sociais de discriminação, promovendo inúmeras situações de exclusão. Esse período é conhecido pela ignorância e rejeição do indivíduo deficiente pela sociedade em geral, que condenava esses sujeitos de uma forma extremamente preconceituosa. De acordo com Mazzotta (1999) o sistema educacional brasileiro pautava-se, até os anos 70, no modelo de integração. Todos os estudantes deviam seguir o mesmo método pedagógico, avançar no mesmo ritmo e serem avaliados da mesma forma. Os alunos que não conseguiam enquadrar-se nos padrões considerados aceitáveis, eram rotulados como "deficientes" ou "excepcionais", devendo ser encaminhados para salas ou escolas "especiais", ou - algumas vezes, para as APAE. As "classes especiais" podiam ser na mesma escola, só que em turno diferente, com crianças de idades diferentes, mas não necessariamente na APAE.

No aspecto de legislação no Brasil, em 1961 a Lei de Diretrizes e Bases da Educação Nacional (LDBEN) no 4024 - fundamenta o atendimento educacional às pessoas com deficiência, chamadas no texto de "excepcionais", onde pontua que: “A Educação de excepcionais, deve, no que for possível, enquadrar-se no sistema geral de Educação, a fim de integrá-los na comunidade."

Em 1971 a Lei ${ }^{\circ}$ 5692, a segunda lei de diretrizes e bases da educação do Brasil, foi promulgada em plena ditadura militar e substituiu a anterior. Nela assinalou que os estudantes com deficiências e os que estavam com atraso considerável (considerando idade regular e ano de matrícula) e os superdotados deverão usufruir de tratamento especial. Essas normas deveriam estar de acordo com as regras fixadas pelos Conselhos de Educação, ou seja, a lei não promovia a inclusão na rede regular, determinando a escola especial como destino certo para essas crianças.

Essa forma preconceituosa começou a ser questionado nos anos 1980. As deficiências dos alunos deixaram de ser vistas como problemas meramente pessoais, passando a ser consideradas como resultantes da falta de empenho das escolas em atender às necessidades diferenciadas de seus estudantes. Com a Constituição Federal do Brasil de 1988 verifica-se especificamente os direitos das pessoas com deficiência em diversos artigos, dentre os quais é possível destacar:

Art. $3^{\circ}$ Constituem objetivos fundamentais da República Federativa do Brasil: Inciso IV - Promover o bem de todos, sem preconceitos de origem, raça, sexo, cor, idade e quaisquer outras formas de discriminação. Art. $5^{\circ}$ Todos são iguais perante a lei. Art. $7^{\circ}$ São direitos dos trabalhadores urbanos e rurais, além de outros que visem à melhoria de sua condição social: Inciso XXXI Proibição de qualquer discriminação no tocante a salário e critérios de admissão do trabalhador portador de deficiência.

Art. $205^{\circ}$ A educação, direito de todos e dever do Estado e da família, será promovida 
e incentivada com a colaboração da sociedade, visando ao pleno desenvolvimento da pessoa, seu preparo para o exercício da cidadania e sua qualificação para o trabalho.

Art. $206^{\circ} \mathrm{O}$ ensino será ministrado com base nos seguintes princípios: Inciso I: Igualdade de condições de acesso e permanência na escola, como um dos princípios para o ensino.

Art. $208^{\circ} \mathrm{O}$ dever do Estado com a educação será efetivado mediante a garantia de: Inciso III: atendimento educacional especializado aos portadores de deficiência, preferencialmente na rede regular de ensino (BRASIL, 1988).

Portanto, é possível dizer que com a Constituição Federal temos um grande avanço para a inserção da educação inclusiva, que trouxe um profundo significado pedagógico e democrático, iniciando o rompimento do modelo tradicional de ensino segregado, iniciando nos anos 90 propostas de uma educação inclusiva.

Nessa perspectiva Mazzotta (1999) diz que os alunos com e sem deficiência devem conviver nas mesmas escolas e salas, aprendendo com suas diferenças e ajudando-se mutuamente a desenvolver suas potencialidades. As escolas devem respeitar as características dos alunos e oferecer alternativas pedagógicas que atendam às suas necessidades comuns e específicas.

Com o advento da Lei $\mathrm{n}^{\circ} 8.069$, ou Estatuto da Criança e do Adolescente (ECA) estabeleceram-se procedimentos nas áreas de saúde, educação, cultura, esporte, lazer, profissionalização, trabalho e atos infracionais, no atendimento a crianças e adolescentes, inclusive os que têm deficiência.

Art. $5^{\circ}$ Nenhuma criança ou adolescente será objeto de qualquer forma de negligência, discriminação, exploração, violência, crueldade e opressão, punido na forma da lei qualquer atentado, por ação ou omissão, aos seus direitos fundamentais.

Art. $11^{\circ}$ É assegurado atendimento integral à saúde da criança e do adolescente, por intermédio do Sistema Único de Saúde, garantido o acesso universal e igualitário às ações e serviços para promoção, proteção e recuperação da saúde.

$\S 1^{\circ} \mathrm{A}$ criança e o adolescente portadores de deficiência receberão atendimento especializado (BRASIL, 1990).

Em 1994 a Política Nacional de Educação Especial, em seu texto foi considerado um atraso, por permiter o ingresso em classes regulares de ensino apenas as crianças com deficiência que “(...) possuem condições de acompanhar e desenvolver as atividades curriculares programadas do ensino comum, no mesmo ritmo que os alunos ditos normais" (PEREIRA, 1980, p. $3)$.

A Lei de Diretrizes e Bases da Educação (LDB - 1996 - Lei $\mathrm{N}^{\circ}$ 9.394) em vigor tem um capítulo específico para a Educação Especial. Nele, afirma-se que "haverá, quando necessário, serviços de apoio especializado, na escola regular, para atender às peculiaridades da clientela de Educação Especial”. O mesmo instrumento legal também afirma que "o atendimento educacional será feito em classes, escolas ou serviços especializados, sempre que, em função das condições específicas dos alunos, não for possível a integração nas classes comuns de ensino regular". Além disso, o texto trata da formação dos professores e de currículos, métodos, técnicas e recursos para atender às necessidades das crianças com deficiência, transtornos globais do desenvolvimento e altas habilidades ou superdotação.

Como pode ser verificado, no cenário educacional existem diversas discussões sobre 
educação inclusiva. De acordo com Munhoz e Pereira (2015) isso ocorreu em decorrência da organização das minorias no âmbito mundial e, para terem garantidos seus direitos de cidadãos, as pessoas portadoras de necessidades especiais passaram a apresentar suas reivindicações, exigindo um ensino de qualidade. Assim, diante do exposto temos um emaranhado de legislação e políticas públicas que permearam todo o contexto de mudanças na educação inclusiva no cenário educacional.

Sobre essa legislação vigente, temos uma entidade que se iniciou em 1954 no município de do Rio de Janeiro conhecida por APAE (Associação de Pais e Amigos dos Excepcionais). Trata-se de um Movimento iniciado em decorrência da chegada ao Brasil de Beatrice Bemis, procedente dos Estados Unidos, membro do corpo diplomático norte americano e mãe de uma portadora de Síndrome de Down. Instigados por Beatrice Bemis, um grupo de pessoas, composto por pais, amigos, professores e médicos de excepcionais, fundou a primeira Associação de Pais e Amigos dos Excepcionais APAE do Brasil. A primeira reunião do Conselho Deliberativo ocorreu em março de 1955, na sede da Sociedade de Pestalozzi do Brasil (SALABERY, 2007).

Pela primeira vez no Brasil, discutia-se a questão da pessoa portadora de deficiência com um grupo de famílias que trazia para o movimento suas experiências como pais de deficientes e, em alguns casos, também como técnicos na área.

Conforme Munhós e Pereira (2015), o Movimento Apaeano, como foi chamado na época, se expandiu para diversos estados do Brasil, com o objetivo de integrar as pessoas com deficiência na comunidade através da valorização e desenvolvimento harmonioso entre família, escola e comunidade. Atualmente as APAE's são o maior movimento social de caráter filantrópico do Brasil e do mundo em sua área de atuação, mantendo seu objetivo inicial de lutar pela defesa de direitos, atendimento e garantia da qualidade de vida das pessoas portadoras de deficiência.

O profissional em Serviço Social, que é o assistente social, pode desenvolver seu trabalho nas mais diversas áreas, inclusive no setor educacional. É necessário que a realidade social contemporânea compreenda a importância que os assistentes sociais têm enquanto agentes críticos envolvidos nas lutas sociais, que atua junto aos usuários das políticas públicas, muitas vezes elaborando-as, executando-as e também as tornando acessíveis.

Como amparo legal, o assistente social trabalha sob a ótica da Política de Assistência Social, conforme debates e estudos já amplamente difundidos, avançando do patamar de assistencialismo para uma nova institucionalidade, manifesta na Constituição Federal do Brasil de 1988 (CF/88), onde a Assistência Social compõe o Tripé do qual fazem parte a Seguridade Social, a Lei Orgânica da Assistência Social - LOAS, de 1993; e, por fim, a Política Nacional de Assistência Social/PNAS de 2004 e pelas Normas Operacionais Básicas do Sistema Único da Assistência Social (NOBSUAS, 2005; NOB-RHSUAS, 2006, e recentemente NOB-SUAS, 2012).

Com relação à Seguridade Social, este 
programa surgiu quando a Constituição Federal entrou em vigor, referindo-se à previdência, à assistência social e também às áreas da saúde. Ou seja, define-se por "Seguridade Social" o conjunto de ações do - Estado que visam atender às necessidades básicas no que tange à saúde, assistência social e previdência. Foi uma inovação porque a legislação no Brasil nem sempre buscou a adoção de medidas assistenciais para proteção de pessoas em situação de necessidade. Na verdade, a Constituição de 1988 foi a primeira a trazer em seu corpo a previsão expressa desse instituto. As outras constituições e normas legais mencionavam apenas o acesso à previdência social ou à saúde, mas nada falavam sobre a assistência social (BRASIL, 1998).

Cabe esclarecer que a Constituição Federal, em seu artigo 203, prevê quem são os destinatários da assistência social, enquanto o artigo 204 direciona-se para as ações governamentais, indicando a fonte de recursos que a custearão e trazendo diretrizes a serem observadas pelos legisladores e administradores futuros.

Já com a Lei Orgânica da Assistência Social - LOAS - Lei $n^{\circ} 8.742$, que regulamenta esse aspecto da Constituição e estabelece normas e critérios para organização da assistência social que é um direito que exige definição de leis, normas e critérios objetivos - estabelece como diretriz a descentralização políticoadministrativa, transferindo para os Estados, Municípios e Distrito Federal, o comando das ações de assistência social. Essa diretriz está presente em vários outros momentos da Lei, incluindo a participação da população e entidades não governamentais, de forma paritária, no processo decisório ao nível local, estadual e nacional, através dos conselhos de Assistência Social (BRASIL, 1993).

Por sua vez, o Sistema Único de Assistência Social (SUAS) criado em 2005, em sua Norma Operacional Básica (NOB), se apresenta descentralizado e participativo, tendo por função a gestão do conteúdo específico da Assistência Social no campo da proteção social brasileira. Consolida o modo de gestão compartilhada, com financiamento e a cooperação técnica entre os três entes federativos que, de modo articulado e complementar, operam a proteção social não contributiva de seguridade social no campo da assistência social (BRASIL, 2005).

Ainda a NOB/2005 organiza as ações da assistência social em dois tipos de proteção social. A primeira é a Proteção Social Básica, destinada à prevenção de riscos sociais e pessoais, por meio da oferta de programas, projetos, serviços e benefícios a indivíduos e famílias em situação de vulnerabilidade social. A segunda é a Proteção Social Especial, destinada a famílias e indivíduos que já se encontram em situação de risco e que tiveram seus direitos violados por ocorrência de abandono, maus-tratos, abuso sexual, abuso de drogas, entre outros aspectos (BRASIL, 2005).

Atualizada, a Norma Operacional Básica de Recursos Humanos (NOB-RH/SUAS/2006), tem como objetivo delinear os principais pontos da gestão pública do trabalho e propor mecanismos reguladores da relação entre gestores e trabalhadores e os prestadores de serviços socioassistenciais, apresentando, para tanto, as primeiras diretrizes para a política de gestão do 
trabalho. Dessa forma, tornou obrigatória a presença de profissionais com expertise, como assistentes sociais, psicólogos e advogados, para o atendimento à população. A partir de 2006, os trabalhadores passaram a ter visibilidade na assistência social.

A NOB SUAS 2012 reafirma a política de assistência social como política de Seguridade Social, afiançadora de direitos, tal como consagrado pela Constituição Federal de 1988 e representa, sem dúvida, uma conquista do Estado, gestores, conselhos, trabalhadores, especialistas, e também da população brasileira, em especial daquela atendida pelo SUAS. Com relação ao trabalho dos assistentes sociais, temos o Código de Ética que, assim como os códigos de ética de outras profissões, define as atribuições e características da profissão. Nele encontram-se princípios fundamentais que devem nortear as práticas destes profissionais, princípios esses que dão suporte para vencer os desafios do cotidiano. Assim temos:

Defesa intransigente dos direitos humanos e recusa do arbítrio e autoritarismo.

Posicionamento em favor da equidade e justiça social, que assegure universalidade de acesso aos bens e serviços relativos aos programas e políticas sociais, bem como sua gestão democrática.

Compromisso com a qualidade dos serviços prestados à população e com o aprimoramento profissional (BRASIL, 1993).

De fato, frente a toda a complexidade social que envolve o exercício profissional dos assistentes sociais, é necessário que haja um projeto profissional sólido para efetivar suas ações na realidade dinâmica da sociedade capitalista. $\mathrm{O}$ primeiro pressuposto para a consolidação do projeto profissional é ter total domínio e compreensão sobre seus princípios e fundamentos centrais, ou seja, especificamente, no projeto ético-político dos assistentes sociais, compreender o princípio da liberdade.

O desafio é a materialização dos princípios éticos na cotidianidade do trabalho, evitando que se transformem em indicativos abstratos, deslocados do processo social. Afirma, como valor ético central, o compromisso com a parceria inseparável, a liberdade. Implica a autonomia, emancipação e a plena expansão dos indivíduos sociais, o que tem repercussões efetivas nas formas de realização do trabalho profissional e nos rumos a ele impressos (IAMAMOTO, 2008, p. 77)

Cabe ressaltar que o assistente social tem suas competências previstas na Lei 8.662/93, em seu artigo $4^{\circ}$ de Regulamentação da Profissão, que prevê, dentre outras:

II - Elaborar, coordenar, executar e avaliar planos, programas e projetos que sejam do âmbito de atuação do Serviço Social com participação.

III - encaminhar providências e prestar orientação social a indivíduos, grupos e à população.

V - Orientar indivíduos e grupos de diferentes segmentos sociais no sentido de identificar recursos e de fazer uso dos mesmos no atendimento e na defesa de seus direitos.

VII - planejar, executar e avaliar pesquisas que possam contribuir para a análise da realidade social e para subsidiar ações profissionais (BRASIL, 1993).

Estes são as principais competências que os assistentes sociais devem realizar para atendimento das demandas existentes no campo da Assistência Social, em prol da qualidade de vida dos usuários desistidos. Ou seja, esse profissional tem o compromisso de garantir e verificar alternativas para viabilizar os direitos das

pessoas. Assim, não deve acolher uma 
determinação institucional se vier a ferir algum direito do cidadão. Esse é um dever ético do assistente social.

Nessa ótica, o assistente social possui habilidade profissional para propor e implementar políticas públicas no atendimento das pessoas com deficiência.

Trabalhar junto das pessoas portadoras de deficiência é atuar na perspectiva de garantia de direitos historicamente constituídos, modificando a realidade, transformando o sujeito em autor de sua história, instigando autonomia. Ressalta-se a importância da constante e permanente formação técnica do assistente social, garantindo o aprimoramento de competência técnica, operativa e intelectual, consolidando assim o compromisso político com as pessoas portadoras de deficiência (TAVARES, 2010, p. 236 apud, MUNHÓS; PEREIRA, 2015, p.10).

Outro ponto importante são os projetos sociais desenvolvidos pelos assistentes sociais. É uma das poucos profissões que possui um projeto coletivo e hegemônico denominado projeto ético-político que tem contornos claramente expressos na lei 8662/93, no código de ética e nas diretrizes curriculares. Na pratica o assistente social participa ativamente das ações elaboradas nos projetos sociais, seja na elaboração do projeto social, nas visitas e entrevistas com o público alvo do projeto, bem como nas ações educativas propostas. Em muitas situações o assistente social em suas ações junto ao público alvo consegue promover autonomia, vínculos familiares, e cidadania (IAMAMOTO, 2009).

Os projetos sociais exigem do assistente social conhecimento da realidade do público alvo; o conhecimento dos meios, e modos de sua utilização, a visão da prática em forma de teoria, e contribui para o estabelecimento das finalidades ou antecipação dos resultados objetivos que se pretende atingir no projeto social.

\section{O Profissional de Serviço Social na APAE}

A análise da atuação do profissional de Serviço Social na educação especial foi realizada numa APAE, fundada no dia 31 de agosto de 1981, numa cidade localizada no Mato Grosso do Sul. Essa APAE -MS tem duas assistentes sociais que desenvolvem suas atividades pautadas na ética, com posicionamento em favor da equidade e justiça social, que assegure universalidade de acesso aos bens e serviços, tido como um dos princípios fundamentais.

A assistente social afirmou que "trabalham desenvolvido ações de inclusão, sem discriminar por questões de inserção de classe social, gênero, etnia, religião, nacionalidade, orientação sexual, identidade de gênero, idade e condição física" (ENTREVISTA 1, maio, 2017). Essa fala aponta diretamente o expresso nos artigos X e XI do Código de Ética Profissional do Assistente Social. Assim, os serviços prestados na APAE -MS buscam a garantia dos direitos da pessoa com deficiência pautada nas ideias de inclusão social, conforme demonstra a transcrição da entrevista de

uma das assistentes sociais da APAE: "tem o dever de se comprometer e de contribuir com a construção da educação inclusiva o que é fundamental para a inclusão social"

(ENTREVISTA 2, maio, 2017), postulado bem explicitado no Código de Ética do profissional de assistente social, que diz: 
Defesa intransigente dos direitos humanos e recusa do arbítrio e autoritarismo.

Posicionamento em favor da equidade e justiça social, que assegure universalidade de acesso aos bens e serviços relativos aos programas e políticas sociais, bem como sua gestão democrática.

Compromisso com a qualidade dos serviços prestados à população e com o aprimoramento profissional (BRASIL, 1993).

Para atender a esses pressupostos, são desenvolvidos projetos sociais na APAE - MS, dentre eles o Projeto Rompendo Barreiras, o Fortalecimento de Vínculos e o Projeto Defesa, Garantia e Direito da Pessoa com Deficiência .

\section{Projeto Rompendo Barreiras}

Tem como objetivo estimular a autonomia quanto aos cuidados de higiene e restabelecer os vínculos, especificamente com o público de vulnerabilidade social e de risco, fortalecendo a convivência familiar e comunitária.

As atividades desenvolvidas são:

Tarde de postura e relaxamento.

Tarde da beleza (cabeleireiro, manicure e pedicure, designer de sobrancelhas e maquiagens).

> Prevenção à violação psicológica no âmbito familiar.

Estratégias para enfrentar a violência psicológica.

Tarde de descontração (bingo, brinde, chá da tarde).

$>$ Palestra sobre autonomia da pessoa com deficiência.

$>$ Higiene doméstica.

Fortalecimento da função protetiva da família.

Palestra sobre prevenção contra o câncer de mama e de câncer de útero.

D Trabalho sobre as potencialidades existentes na família.

Palestra sobre responsabilidade.

Especificamente neste projeto estão inseridos a pessoa com deficiência e sua família que busca desenvolver a autonomia dos participantes. $\mathrm{Na}$ acepção da assistente social "em algumas famílias

é possível perceber que existe um cuidado exagerado com a pessoa que tem necessidade especial, e tarefas rotineiras acabam sendo realizados por familiares, por julgarem a pessoa com deficiência incapaz, o que na verdade é um grande equívoco" (ENTREVISTA 2, maio, 2017).

Sob essa perspectiva, a assistente social realiza palestras, rodas de conversar, procurando orientar os familiares a estimularem a autonomia das pessoas com deficiência, passando-lhes confiança, salientando que é possível fazer algumas coisas, sempre respeitando as limitações de cada um. Essas ações estão em consonância com as competências do assistente social previstas na Lei 8.662/93 de Regulamentação da Profissão,

conforme o artigo $4^{\circ}$, onde se lê: "elaborar, coordenar, executar e avaliar planos, programas e projetos que sejam do âmbito de atuação do

Serviço Social com participação, encaminhar providências e prestar orientação social a indivíduos, grupos e à população".

A inserção do assistente social na educação justifica-se a partir de uma compreensão ampla do processo de ensinar e aprender, contemplando as dimensões cognitiva, afetiva e social, sendo esta última o alvo primordial do Serviço Social. O serviço social da APAE - MS desenvolve ações socioeducativas de cunho humanizador junto às 
famílias, com o objetivo de facilitar a relação interpessoal de seus membros.

Isso vai ao encontro da legislação vigente, a exemplo disso temos, a NOB/2005, que estabelece que a primeira ação é a Proteção Social Básica, destinada à prevenção de riscos sociais e pessoais, por meio da oferta de programas, projetos, serviços e benefícios a indivíduos e famílias em situação de vulnerabilidade social (BRASIL, 2005). Assim, o projeto Rompendo Barreiras, está vinculado ao respeito mútuo, aos limites individuais e, ainda, a não invasão dos espaços e a liberdade do outro.

\section{Projeto Fortalecimento de Vínculo}

O objetivo deste projeto é trabalhar as relações, tendo como foco a pessoa deficiente $\mathrm{e}$ sua interação com o familiar. Sobretudo, buscase contribuir com a modificação da compreensão que as mães possuem, buscando uma relação positiva, maior vinculação e aceitação da deficiência por parte do familiar.

Atividades desenvolvidas:

Reunião quinzenal com as famílias vítimas de vulnerabilidade, abordando a problemática levantada pelas participantes, através de dinâmicas, conversas e vídeos.

$>$ Quando necessário, realização de visita domiciliar.

Salabery (2015) afirma que o portador de deficiência é um ser humano dotado de sentimentos, emoções e elaborações mentais e que, por isso, sua condição deve ser encarada, como uma de suas múltiplas características e não como a única configuração possível de sua individualidade. [...] há graus diferentes de possibilidades em cada pessoa portadora de deficiência. A assistente social ressaltou que;

é na família que ocorrem as trocas, as participações e as descobertas. É na convivência com a mãe que a criança ouve as canções de ninar, sente o aconchego na alimentação, na proteção contra o frio e o calor, nos cuidados básicos. Nas relações entre os familiares desenvolve-se a cumplicidade entre os membros, cujas identidades propiciam todo um clima de proteção e confiança no mundo que a criança terá de enfrentar (ENTREVISTA 1, maio, 2017).

Por isso, o projeto Fortalecimento de Vínculos tem caráter preventivo e proativo, realizado em grupos, de modo a garantir aquisições progressivas aos seus usuários, de acordo com seu ciclo de vida. Trata-se de um Serviço de Proteção Social Básica, e quando necessário ocorrem atendimentos nos domicílios buscando atender as demandas das pessoas com deficiência e possibilitar seu empoderamento e o de suas famílias, conforme preconiza o Sistema Único de Assistência Social. A assistente social da APAE-MS afirmou que o projeto tem atingido os objetivos proposto.

Projeto Defesa, Garantia e Direito da Pessoa Com Deficiência

O objetivo geral do projeto é possibilitar a integração da família configurando-a como rede de apoio na proteção social, fortalecendo a participação política do usuário e da família na defesa e garantia da pessoa com deficiência intelectual e múltipla.

Atividades desenvolvidas:

Palestras sobre o Benefício de Prestação 
Continuada (BPC).

Orientações sobre BPC.

$>$ Encaminhamentos.

$>$ Atendimento à família sobre os benefícios garantidos por lei.

Esse projeto é desenvolvido para orientar a família sobre o direito ao Benefício Eventual, garantido a idosos e pessoas com deficiência física. É um benefício de 01 (um) salário mínimo mensal pago às pessoas idosas com 65 (sessenta e cinco) anos ou mais, conforme o estabelecido no Art. 34 da Lei $n^{\circ} 10.741$, de $1^{\circ}$ de outubro de 2003 - o Estatuto do Idoso, e às pessoas com deficiência incapacitadas para a vida independente e para o trabalho. Está previsto no artigo $2^{\circ}$, inciso IV, da Lei Orgânica da Assistência Social - LOAS (Lei no 8.742 de 07 de dezembro de 1993) e regulamentado pelo Decreto $\mathrm{n}^{\circ} 1.744$, de 08 de dezembro de 1995 e pela Lei $\mathrm{n}^{\circ}$ 9.720, de 20 de novembro de 1998 e está em vigor desde $1^{\circ}$ de janeiro de 1996. Quanto a isso, a Assistente Social pontuou que;

o projeto é um caminho em que, por meio do acompanhamento dos beneficiários, garante-se o cumprimento da Lei, pois é um direito da pessoa com deficiência receber o benefício. Para ter acesso a tal benefício, de acordo com Lei Orgânica da Assistência Social, o formulário pode ser preenchido por qualquer pessoa e assinado pelo responsável pelo sujeito de direito, não é necessário nenhum intermediário. (ENTREVISTA 2, maio, 2017).

Em decorrência das dificuldades das famílias nos trâmites legais, hoje o assistente social, continua sendo uma grande referência no encaminhamento deste benefício, sendo ainda procurado para este tipo de preenchimento. No encaminhamento, cabe ao profissional anexar um "parecer" referenciando a confirmação das condições sócio econômicas do núcleo sociofamiliar da PPD, sob pena de indeferimento pelo Instituto Nacional do Seguro Social (BRASIL, 2005).

Cabe ressaltar que a atuação do assistente social, com relação a pessoas com deficiência em nenhum momento se restringe ao encaminhamento para obtenção do Benefício de Prestação Continuada, que é apenas uma das formas de inclusão social destes segmentos na sociedade. O trabalho do assistente social busca promover ações quanto a este público alvo específico, articuladas à promoção e à ampliação dos direitos sociais, incluindo o reconhecimento da cidadania desses sujeitos.

\section{CONSIDERAÇÕES FINAIS}

Diante do exposto é possível perceber que o Assistente Social desempenha um papel bem importante na APAE, emu ma cidade do Mato Grosso do Sul. As profissionais entrevistadas demonstram grande comprometimento com a população atendida, e têm desenvolvido um trabalho embasado no Projeto Ético-Político do Serviço Social.

Acredita-se que tal comprometimento é fundamental para o provimento das necessidades básicas de cada indivíduo e de sua família, garantindo um mínimo de dignidade para a vida dessas pessoas. Os projetos desenvolvidos pelas profissionais procuram diminuir as situações de vulnerabilidades sociais, as fragilidades nos vínculos afetivos e potencializar a construção de uma rede de apoio social e de inclusão. 


\section{REFERÊNCIAS BIBLIOGRÁFICAS}

BRASIL. Estatuto da Criança e do Adolescente. Lei 8069, 1990.

\section{Constituição da República}

Federativa do Brasil. Diário Oficial, 1998.

. Lei de Diretrizes e Base de 1961 - Lei

4024 de 20 de dezembro de 1961. Disponível em:

www.planalto.gov.br/ccivil_03/leis/L4024.htm. Acesso: 28 mai. 2017.

Código de Ética Profissional de

Serviço Social. Brasília, Atlas 1993.

. Lei Orgânica da Assistência Social.

Lei $n^{\circ} 8742$ de 07 de dezembro de 1993.

. Dispõe sobre a profissão de Assistente

Social e dá outras providências Lei no. 8.662, de 7 de junho de1993.

CFESS (Conselho Federal de Serviço Social) Resolução CFESS no 273, de 13 de março de 1993, Código de Ética do Assistente Social).

Parâmetros para Atuação de Assistentes Sociais na Política de Assistência Social. Série: Trabalho e Projeto Profissional nas Políticas Sociais. Brasília, 2011.

GIL, Antônio Carlos. Como elaborar projetos de pesquisa. $5^{\circ}$ ed. São Paulo: Atlas, 2008.

IAMAMOTO, M. V. O trabalho do assistente social frente às mudanças do padrão de acumulação e de regulação social. In:

Capacitação em Serviço Social e Política Social. Módulo 1: Crise contemporânea, questão social e Serviço Social. Brasília: CEAD,1999.

\section{O Serviço Social na}

Contemporaneidade: trabalho e formação profissional. $3^{a}$ ed. São Paulo: Cortez, 2000.

LUNA, Maria Aline Ladim. As contribuições do serviço social para a pessoas com deficiência no contexto escolar. Revista Interfaces: Vol. 3(11), pp. 87-94. Julho, 2016.

Mazzotta MJS. Educação especial no Brasil: história e políticas públicas. 2 ed. São Paulo: Cortez; 1999.
MUNHÓS, Patrícia Souza; PEREIRA, Rejane. A política de educação de inclusão das pessoas com deficiências e a atuação do assistente social. Revista Maiêutica em Serviço Social, Indaial, v. 3, n. 1, p. 7-11, 2015.

PEREIRA, Olívia et al. Educação especial: atuais desafios. Rio de Janeiro: Interamericana, 1980.

SALABERRY, Neusa T. Machado. A APAE educadora: na prática de uma unidade da APAE de Porto Alegre. Dissertação (Mestrado em Educação) - PUCRS, 2007.

SASSAKI, Romeu Kazumi. Inclusão: construindo uma sociedade para todos. $3^{\circ}$. ed. Rio de Janeiro: WVA, 1997.

\section{Como citar este artigo (Formato ABNT):}

EL-ABED, Naila Muhammad. Atuação do profissional do serviço social na educação especial. Educação, Psicologia e Interfaces, vol.1, n.1, p. 44-56, 2017. DOI: https://doi.org/10.37444/issn-2594-5343.v1i1.1

Recebido: 04/03/2017. Aceito: 05/04/2017. 